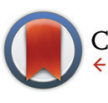

CrossMark \& click for updates

Cite this: Dalton Trans., 2016, 45 15041

Received 1st August 2016, Accepted 17th August 2016

DOI: $10.1039 / c 6 d t 03048 c$

www.rsc.org/dalton

\section{Structure property relationships affecting the proton conductivity in imidazole loaded Al-MOFs $\uparrow$}

\author{
T. Homburg, ${ }^{a}$ C. Hartwig, ${ }^{a}$ H. Reinsch, ${ }^{a}$ M. Wark ${ }^{b}$ and N. Stock*a \\ The structures of the imidazole loaded derivatives of Al-MIL-53 $\left[\mathrm{Al}(\mathrm{OH})\left(1,4-\mathrm{BDC}-\left(\mathrm{CH}_{3}\right)_{x}\right)\right](x=0,1,2)$ and \\ CAU-11 ([Al(OH)(SDBA)]) (1,4- $\mathrm{H}_{2} \mathrm{BDC}=$ terephthalic acid; $\mathrm{H}_{2} \mathrm{SDBA}=4,4$ '-sulfonyldibenzoic acid) were \\ determined from powder $\mathrm{X}$-ray diffraction data. Impedance spectroscopy measurements were carried \\ out to evaluate their proton conductivities under anhydrous conditions at temperatures up to $110{ }^{\circ} \mathrm{C}$. In \\ Al-MIL-53- $\left(\mathrm{CH}_{3}\right)_{x_{-}} \mathrm{HIm}(x=0,1,2)$ the formation of hydrogen bonds between the framework and the \\ guest molecules results in a decrease in proton conductivity $\left(x_{0}=1.7 \times 10^{-6}, x_{1}=1.9 \times 10^{-8}\right.$ and $x_{2}=1.7$ \\ $\times 10^{-9} \mathrm{~S} \mathrm{~cm}^{-1}$ at $110{ }^{\circ} \mathrm{C}$ and $E_{\text {act }}=0.42,0.41$ and $0.46 \mathrm{eV}$, for 0,1 and $2 \mathrm{CH}_{3}$-groups, respectively). The \\ highest conductivity has been measured for CAU-11_HIm with $3.0 \times 10^{-4} \mathrm{~S} \mathrm{~cm}^{-1}$ at $110^{\circ} \mathrm{C}\left(E_{\text {act }}=0.19\right.$ \\ $\mathrm{eV}$ ), where no host-guest hydrogen bonding interactions are observed.
}

\section{Introduction}

Within the field of renewable energy and future mobility, hydrogen and methanol are common energy carriers and the most prominent candidates for utilization in fuel cells. ${ }^{1}$ Inside such fuel cells the well-known combustion reaction of $\mathrm{H}_{2}$ and $\mathrm{O}_{2}$ to $\mathrm{H}_{2} \mathrm{O}$ is split into two electrochemical half reactions (anode: $\mathrm{H}_{2} \rightarrow 2 \mathrm{H}^{+}+2 \mathrm{e}^{-}$and cathode: $\frac{1}{2} \mathrm{O}_{2}+2 \mathrm{e}^{-} \rightarrow \mathrm{O}^{2-}$ ). In order to spatially separate the reaction, an external circuit for the electron transfer and an electrolyte for the flow of protons is needed. Most often these electrolytes use a water mediated system to transport the protons from the anode to the cathode. ${ }^{2-4}$ Within this context, the development of coordination polymers (CPs) as anhydrous proton conductive materials has recently attracted a lot of interest. ${ }^{5-12}$ Systematic studies have proven that membranes made of certain CPs do not show any fuel crossover and can be operated at temperatures above $100{ }^{\circ} \mathrm{C}^{13}$ The latter issue is an important shortcoming of Nafion, the state of the art material in fuel cells. Not only is the mechanical stability of the Nafion membrane limited by its hydration level, but also the proton conduction itself strongly depends on the relative humidity. ${ }^{14,15}$ This implies a limitation in the operating temperature due to the

\footnotetext{
${ }^{a}$ Institut für Anorganische Chemie Christian-Albrechts-Universität zu Kiel, Max-EythStrasse 2, 24118 Kiel, Germany. E-mail: stock@ac.uni-kiel.de

${ }^{b}$ Institut für Chemie, Carl von Ossietzky Universität Oldenburg, Carl-von-OssietzkyStrasse 9-11, 26129 Oldenburg, Germany

$\dagger$ Electronic supplementary information (ESI) available: Synthesis details, IR-, NMR- and impedance spectroscopy, thermal analyses, Rietveld refinements. See DOI: $10.1039 / \mathrm{c} 6 \mathrm{dt} 03048 \mathrm{c}$
}

removal of water from the Nafion pores above $80{ }^{\circ} \mathrm{C} .{ }^{16-18} \mathrm{In}$ recent years, several CPs and MOFs (metal-organic frameworks) have been investigated regarding their proton conduction properties, some of which show a similar value as Nafion $\left(1 \times 10^{-2} \mathrm{~S} \mathrm{~cm}^{-1}\right)$ in the presence of water. ${ }^{19-25}$ Also, alternative molecules that act as proton shuttles have been studied. For example, 1,2,4-triazole was incorporated during the synthesis of $\mathrm{Na}_{3}$ (THBS) (THBS $^{3-}=2,4,6$-trihydroxy-1,3,5-benzenetrisulfonate) and the final product exhibits an anhydrous proton conductivity of $5 \times 10^{-4} \mathrm{~S} \mathrm{~cm}^{-1}$ at $150{ }^{\circ} \mathrm{C} .{ }^{11}$ In addition, adsorption of histamine into $[\mathrm{Al}(\mathrm{OH})(1,4-\mathrm{NDC})]\left(\mathrm{NDC}^{2-}=1,4\right.$ naphthalenedicarboxylate) leads to a host-guest system with a high anhydrous proton conductivity of $1.7 \times 10^{-3} \mathrm{~S} \mathrm{~cm}^{-1}$ at $150{ }^{\circ} \mathrm{C} .{ }^{12}$ Recently, imidazole (Him) was also incorporated into the pores of UiO- $67,\left[\mathrm{Zr}_{6} \mathrm{O}_{4}(\mathrm{OH})_{4}(\mathrm{BPDC})_{6}\right]\left(\mathrm{BPDC}^{2-}=\right.$ biphenyl$4,4^{\prime}$-dicarboxylate) and a conductivity of more than $10^{-3} \mathrm{~S}$ $\mathrm{cm}^{-1}$ at $120{ }^{\circ} \mathrm{C}$ in an anhydrous environment was observed, ${ }^{7}$ which was explained by the very weak host guest interactions. For porous coordination polymers with MIL-53-type structure it has been shown that the hydrophobisation of the framework in combination with the use of organic guest molecules can enhance the proton conductivity in such systems. ${ }^{26}$ The 3D framework of MIL-53 is built up of infinite chains of trans corner-sharing $\mathrm{AlO}_{4}(\mu-\mathrm{OH})_{2}$ polyhedra, which are connected by 1,4-benzenedicarboxylate $\left(\mathrm{BDC}^{2-}\right)$ molecules, to form onedimensional rhombic-shaped channels..$^{21,27,28}$ Bureekaew et al. synthesised MIL-53 frameworks using $1,4-\mathrm{H}_{2} \mathrm{NDC}$ and 1,4$\mathrm{H}_{2} \mathrm{BDC}$ as linker molecules and subsequently impregnated the frameworks with HIm molecules. ${ }^{26}$ The different steric influences of the linker molecules leads to different pore shapes and host-guest interactions, which was demonstrated via solid-state ${ }^{2} \mathrm{H}$-NMR spectroscopy. Impedance spectroscopy 
showed that the conductivity of the compounds is correlated with the dynamic properties of imidazole adsorbed within the pores. In Al-MIL-53-1,4-NDC_HIm, the adsorbed HIm molecules can move more freely $\left(2.2 \times 10^{-5} \mathrm{~S} \mathrm{~cm}^{-1}\right.$ at $\left.120{ }^{\circ} \mathrm{C}\right)$ than in Al-MIL-53-BDC_HIm $\left(1.0 \times 10^{-7} \mathrm{~S} \mathrm{~cm}^{-1}\right.$ at $\left.120{ }^{\circ} \mathrm{C}\right)$. Furthermore, Eisbein et al. used molecular dynamics simulations to study the proton transfer in an imidazole loaded AlMIL-53 structure. ${ }^{29}$ They observed an ordering effect of the imidazole molecules through interactions with hydrophilic groups of the framework. This supports the finding of Bureekaew et al. and suggested a general positive effect of hydrophobicity on the proton conductivity.

Here, we report the results of our systematic study on the influence of the pore structure of Al-MOFs on their proton conductivity. In this context, we have synthesized various, derivatives of Al-MIL-53 $\left[\mathrm{Al}(\mathrm{OH})\left(1,4-\mathrm{BDC}-\left(\mathrm{CH}_{3}\right)_{x}\right)\right](x=$ $0,{ }^{27} 1,{ }^{28} 2$ ) and the recently reported MOF CAU-11 [ $\mathrm{Al}(\mathrm{OH})$ (SDBA) $]\left(4,4^{\prime}\right.$-sulfonyldibenzoate $\left.=\mathrm{SDBA}^{2-}\right){ }^{30}$ These MOFs were loaded with imidazole molecules and their structures, as well as their proton conductivities were determined at various temperatures.

\section{Experimental}

\section{Materials}

All employed chemicals are commercially available and were used without further purification.

\section{Methods}

The syntheses were carried out in custom-made steel autoclaves containing a Teflon insert with a volume of $30 \mathrm{~mL}$. Powder X-ray diffraction (PXRD) data was measured on a STOE Stadi $\mathrm{P}$ diffractometer with $\mathrm{Cu}-\mathrm{K}_{\alpha 1}$-radiation, equipped with a PSD detector. Thermogravimetric experiments were

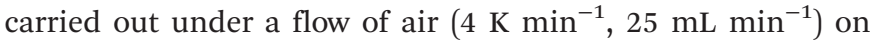
a Netzsch STA 409 CD analyzer. ${ }^{1} \mathrm{H}-\mathrm{NMR}$ spectra were measured after dissolution of the imidazole loaded MOFs in $5 \mathrm{wt} \% \mathrm{NaOD} / \mathrm{D}_{2} \mathrm{O}$ on a Bruker DRX 200 spectrometer. Nitrogen physisorption isotherms were recorded after activation at $150{ }^{\circ} \mathrm{C}$ under reduced pressure using a BELSorpMax. Force-field calculations for structural optimisations were performed using Materials Studio ${ }^{31}$ and all processing of PXRD data was carried out using TOPAS. ${ }^{32}$ Proton conductivity was determined by impedance spectroscopy $(\text { IS })^{33}$ using a ZahnerZennium electrochemical workstation and a custom-made cell over the frequency range 1 to $10^{6} \mathrm{~Hz}$ and employing an oscillating voltage of $100 \mathrm{mV}$. The microcrystalline samples were homogenized and incorporated into a stack comprising of the sample sandwiched between two graphitic slices. The stack was placed in a PTFE sample holder, where two stainless steel electrodes (diameter $8 \mathrm{~mm}$ ) served as working and counter electrode. The sample holder was placed in a temperature-controlled stainless steel chamber and pressed with an angular moment of $30 \mathrm{cNm}$ to obtain pellets (thickness between 0.3 and $1.0 \mathrm{~mm}$ ). ${ }^{34}$ Before each series of temperature-dependent measurements, the samples were equilibrated for 4-6 hours at $110{ }^{\circ} \mathrm{C}$. Each sample was equilibrated for additional 2 hours at the desired temperature $\left(110,100,90\right.$, and $80^{\circ} \mathrm{C}$ ), before measuring each data point. Every measurement was carried out three times to ensure reproducibility, and at least two pellets of each hostguest system were studied. The proton conductivity (eqn (1)) was obtained by using the Ohmic resistance of the samples determined by IS.

$$
\sigma=\frac{L}{A \cdot R}
$$

$\sigma$ : proton conductivity, $L$ : sample thickness, $A$ : sample crosssection area, $R$ : Ohmic resistance.

A Bode phase plot of the impedance was used to determine the Ohmic resistance. In a Bode plot the impedance corresponding to the phase shift closest to zero is approximately equal to the Ohmic resistance of the sample.

\section{Synthesis}

Al-MIL-53 (1) was synthesized using a mixture of 1,4 benzenedicarboxylic acid $\left(\mathrm{H}_{2} \mathrm{BDC}, 0.288 \mathrm{~g}, 1.7 \mathrm{mmol}\right), \mathrm{Al}\left(\mathrm{NO}_{3}\right)_{3} \cdot 9 \mathrm{H}_{2} \mathrm{O}$ $(1.30 \mathrm{~g}, 3.5 \mathrm{mmol})$ and $5 \mathrm{~mL}$ water, which was heated in an oven at $200{ }^{\circ} \mathrm{C}$ for $12 \mathrm{~h}$ (heating and cooling within $1 \mathrm{~h}$, each). The resulting precipitate was filtered off, washed with DMF and water, and dried in air. Further synthesis details have been reported elsewhere. ${ }^{27}$

Al-MIL-53- $\mathrm{CH}_{3}$ (2) was synthesized from a mixture of $\mathrm{AlCl}_{3} \cdot 6 \mathrm{H}_{2} \mathrm{O} \quad(1 \mathrm{~g}, 4.16 \mathrm{mmol})$, methylterephthalic acid $\left(\mathrm{H}_{2} \mathrm{BDC}-\mathrm{CH}_{3}, 0.75 \mathrm{~g}, 4.16 \mathrm{mmol}\right)$ and $5 \mathrm{~mL}$ water using the same temperature program. Further details can be found in ref. 28. The ligand $\mathrm{H}_{2} \mathrm{BDC}-\mathrm{CH}_{3}$ was synthesized according to a previously reported procedure. ${ }^{35}$

Al-MIL-53- $\left(\mathrm{CH}_{3}\right)_{2}$ (3) was obtained from a mixture of $\mathrm{AlCl}_{3} \cdot 6 \mathrm{H}_{2} \mathrm{O}(0.314 \mathrm{~g}, 1.30 \mathrm{mmol})$ and $\mathrm{H}_{2} \mathrm{BDC}-\left(\mathrm{CH}_{3}\right)_{2}(0.127 \mathrm{~g}$, $0.65 \mathrm{mmol}$ ) in $5 \mathrm{~mL}$ water. The steel autoclave was kept at $200{ }^{\circ} \mathrm{C}$ for $24 \mathrm{~h}$ with heating up and cooling down for $1 \mathrm{~h}$. The as-synthesized form (3-as) contains guest molecules and was activated in a two-step procedure similar to Al-MIL-53- $\mathrm{CH}_{3}$. Therefore, 3-as was heated in $N, N$-dimethylformamide (DMF, $60 \mathrm{~mL}$ ) at $155^{\circ} \mathrm{C}$ for $24 \mathrm{~h}$. The filtered solid was washed with water and dried in air, and the narrow pore phase of 3 was obtained.

CAU-11 (4), [Al(OH)(SDBA) $]$ (4,4'-sulfonyldibenzoate = $\mathrm{SDBA}^{2-}$ ), was synthesized from a mixture of $\mathrm{AlCl}_{3} \cdot 6 \mathrm{H}_{2} \mathrm{O}$ (724 mg, $3 \mathrm{mmol}$ ), $\mathrm{H}_{2}$ SDBA (268 mg, $1.2 \mathrm{mmol}$ ), $2 \mathrm{M}$ aqueous solution of $\mathrm{NaOH}(1.8 \mathrm{~mL}, 3.6 \mathrm{mmol})$, and $18.2 \mathrm{~mL} \mathrm{H}_{2} \mathrm{O} .{ }^{30}$ The reaction was performed under conventional heating at $150{ }^{\circ} \mathrm{C}$ for $12 \mathrm{~h}$ (heating and cooling within $1 \mathrm{~h}$, respectively). The resulting precipitate was filtered off and washed with DMF under microwave heating at $150{ }^{\circ} \mathrm{C}$ for $1 \mathrm{~h}$, filtered again, washed with water and dried in air.

\section{Preparation of imidazole-loaded frameworks}

The water containing MOFs 1-4 ( 30 mg) were placed in a $2 \mathrm{~mL}$ Teflon insert, respectively (Fig. S1†). Another $30 \mathrm{~mL}$ 


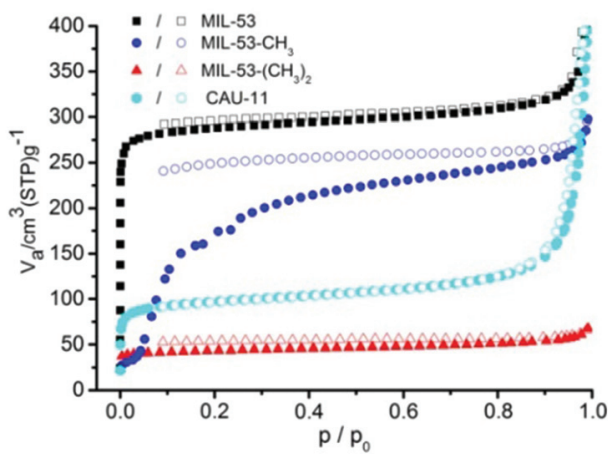

Fig. 1 Sorption isotherms of the host materials Al-MIL-53, Al-MIL-53$\left(\mathrm{CH}_{3}\right), \mathrm{Al}-\mathrm{MIL}-53-\left(\mathrm{CH}_{3}\right)_{2}$ and $\mathrm{CAU}-11$.

Teflon insert was filled with $500 \mathrm{mg}$ of imidazole (HIm). The smaller insert was placed into the larger Teflon sleeve and placed in a steel autoclave at $120^{\circ} \mathrm{C}$ for $12 \mathrm{~h}$, with $1 \mathrm{~h}$ heating up and $1 \mathrm{~h}$ cooling down to yield 1_HIm, 2_HIm and 3_HIm, respectively. 4_HIm was obtained after $4 \mathrm{~h}$ at $120^{\circ} \mathrm{C}$. PXRD patterns of the host frameworks and the intercalated compounds confirmed that the framework structures were maintained (Fig. 1). The amount of loaded imidazole was determined by thermogravimetric analysis, NMR-spectroscopy and Rietveld refinement.

\section{Results and discussion}

Four different microporous host materials, the three MIL-53type compounds MIL-53, MIL-53- $\mathrm{CH}_{3}$ and MIL-53-( $\left.\mathrm{CH}_{3}\right)_{2}$ and CAU-11, were synthesized under solvothermal reaction conditions. The host materials were loaded using an excess of imidazole (HIm) as guest molecules. All samples were characterised by PXRD (Fig. 2A-D). For MIL-53-type hosts, activation and loading with imidazole molecules leads to a change of PXRD patterns due to the "breathing" behaviour (lp = large pore form, $\mathrm{np}=$ narrow pore form). All three MIL-53 compounds exhibit a large pore conformation upon loading with imidazole molecules. In contrast, in CAU-11 no changes of the reflection positions are observed upon activation and guest loading. The presence of guest molecules leads only to small differences in relative intensities of the reflections.

Nitrogen sorption experiments were performed (Fig. 1; Table 1) prior to HIm impregnation. The three MIL-53 derivatives exhibit very different sorption isotherms which is due to the presence of the $-\mathrm{CH}_{3}$ groups. The specific surface areas and micropore volumina for Al-MIL-53 $\left(1424 \mathrm{~m}^{2} \mathrm{~g}^{-1}, 0.53 \mathrm{~cm}^{3}\right.$ $\left.\mathrm{g}^{-1}\right)$ and CAU-11 $\left(354 \mathrm{~m}^{2} \mathrm{~g}^{-1}, 0.17 \mathrm{~cm}^{3} \mathrm{~g}^{-1}\right)$ are in agreement with the values reported in the literature $\left(1590 \mathrm{~m}^{2} \mathrm{~g}^{-1}\right.$, $0.54 \mathrm{~cm}^{3} \mathrm{~g}^{-1}$ and $\left.350 \mathrm{~m}^{2} \mathrm{~g}^{-1}, 0.17 \mathrm{~cm}^{3} \mathrm{~g}^{-1}\right) \cdot{ }^{27,30}$ For AlMIL-53- $\mathrm{CH}_{3}$, only the micropore volume has been reported, which also compares well to our results $\left(0.33 \mathrm{~cm}^{3} \mathrm{~g}^{-1}\right.$, literature $\left.=0.32 \mathrm{~cm}^{3} \mathrm{~g}^{-1}\right)$. As expected, Al-MIL-53- $\left(\mathrm{CH}_{3}\right)_{2}$ has the smallest specific surface area $\left(109 \mathrm{~m}^{2} \mathrm{~g}^{-1}\right)$ and micropore volume $\left(0.05 \mathrm{~cm}^{3} \mathrm{~g}^{-1}\right)$ of the three Al-MIL-53-type compounds.
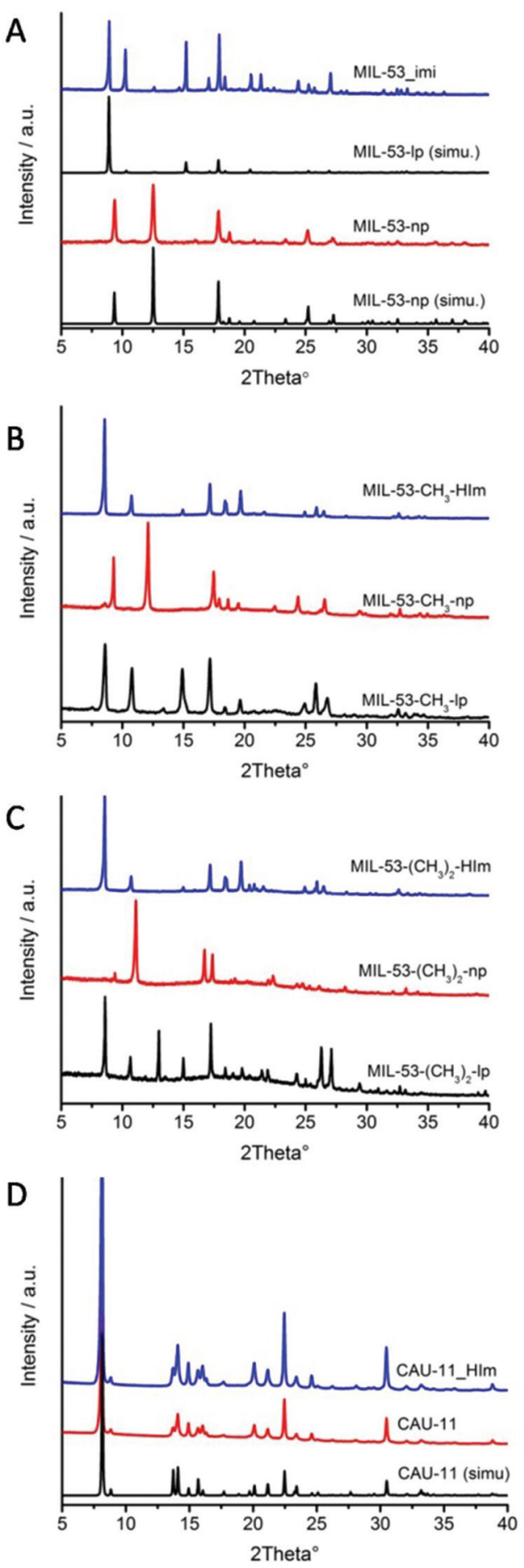

Fig. 2 PXRD patterns of: (A) Al-MIL-53 simulated patterns of narrow pore (np) and large pore (lp) form compared to the synthesized compounds; (B) Al-MIL-53- $\left(\mathrm{CH}_{3}\right)$ and (C) Al-MIL-53- $\left(\mathrm{CH}_{3}\right)_{2}$ experimental patterns of $n p$ (narrow pore) and lp (large pore) in comparison with the impregnated compounds. (D) PXRD patterns of CAU-11 simulated, after washing and after impregnation with HIm molecules.

Quantitative analyses yielding the number of intercalated guest molecules per formula unit were established by TGmeasurements and NMR spectroscopy. 
Table 1 Comparison of the specific surface area $\left(S_{\mathrm{BET}}\right)$ and the micropore volumes $\left(V_{\text {mic }}\right)$ of the host compounds 1-4 with values reported in the literature $27,28,30$

\begin{tabular}{lllll}
\hline Compound & $\begin{array}{l}S_{\mathrm{BET}} \text { lit } \\
{\left[\mathrm{m}^{2} \mathrm{~g}^{-1}\right]}\end{array}$ & $\begin{array}{l}S_{\mathrm{BET}} \\
{\left[\mathrm{m}^{2} \mathrm{~g}^{-1}\right]}\end{array}$ & $\begin{array}{l}V_{\mathrm{mic}} \text { lit } \\
{\left[\mathrm{cm}^{3} \mathrm{~g}^{-1}\right]}\end{array}$ & $\begin{array}{l}V_{\mathrm{mic}} \\
{\left[\mathrm{cm}^{3} \mathrm{~g}^{-1}\right]}\end{array}$ \\
\hline Al-MIL-53 & 1590 & 1424 & 0.54 & 0.53 \\
Al-MIL-53-($\left(\mathrm{CH}_{3}\right)$ & - & 146 & 0.32 & 0.33 \\
Al-MIL-53-($\left(\mathrm{CH}_{3}\right)_{2}$ & - & 109 & - & 0.05 \\
CAU-11 & 350 & 354 & 0.17 & 0.17
\end{tabular}

\section{Quantification of guest loading}

The amount of imidazole molecules in $\mathbf{1}_{-}, \mathbf{2}_{-}, \mathbf{3}_{-}$and $\mathbf{4}$ HIm was evaluated by dissolving the host-guest compounds in $5 \mathrm{wt}$ $\% \mathrm{NaOD} / \mathrm{D}_{2} \mathrm{O}$ and measuring ${ }^{1} \mathrm{H}-\mathrm{NMR}$ spectra. Integration of the signals yields the molar ratios of imidazole: linker molecules (Fig. S6-S9, $\uparrow$ Table 2). No additional signals due to DMF or its decomposition products in water were observed in the ${ }^{1} \mathrm{H}$-NMR spectra.

TGA traces of the compounds 2_, 3_ and 4_HIm show two steps of weight loss, respectively (Fig. S2-S4†). The weight loss between 120 and $300{ }^{\circ} \mathrm{C}$ can be assigned to the desorption of imidazole molecules, whereas the second step is due to the combustion of the host framework. A closer look at the TGA data of 1_HIm (Fig. S1†) strikes out two additional steps. The first one from $50-100{ }^{\circ} \mathrm{C}$ ( $\mathrm{ca}$. 1\%) was assigned to weakly bonded water molecules. The following two successive steps (between 120-190 and $195-270^{\circ} \mathrm{C}$ ) are attributed to the loss of imidazole molecules, suggesting varying strengths of host-guest interactions within the framework. The combustion of the framework starts around $430{ }^{\circ} \mathrm{C}$. Similar observations were reported by S. Bureekaew et al. for HIm in Al-MIL-53 and are confirmed by the structure analysis of 1_HIm (see Crystal structures).

The results from TGA and NMR are consistent. Molar ratios of linker to imidazole between $1: 1.1$ and $1: 1.3$ were observed in 1-4_HIm (Table 2). In the case of 1_HIm, loadings between 1.1 and 1.3 were found, however, the IS measurements did not show any change in conductivity for the samples with different degrees of loading.

\section{Proton conductivity}

Subsequently, the proton conductivity of the imidazole loaded MOFs was measured under anhydrous conditions (relative

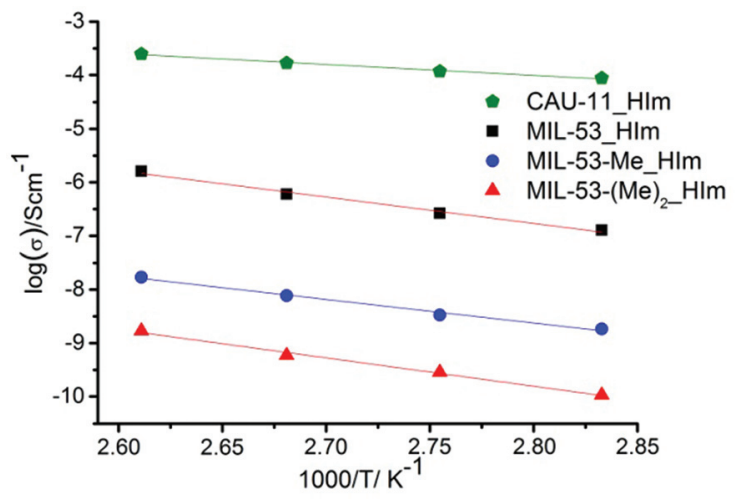

Fig. 3 Comparison of the Arrhenius plots of 1_HIm (MIL-53_HIm), 2_HIm (MIL-53- $\left.\mathrm{CH}_{3} \_\mathrm{HIm}\right), 3 \_\mathrm{HIm}$ (MIL-53- $\left(\mathrm{CH}_{3}\right)_{2}$ HIm) and 4_HIm (CAU-11_HIm). The resulting activation energies are displayed in Table 3.

humidity of $0 \%$ ) and at temperatures between 80 and $110{ }^{\circ} \mathrm{C}$ by impedance spectroscopy. The proton conductivity of guestfree 1-4 is negligibly low (not shown), but varies strongly between the four title compounds 1-4_HIm (Fig. 3).

For all loaded compounds, an increase in temperature leads to an increase in conductivity and a linear correlation of $\log \sigma$ vs. $1 / T$ is observed. For 4_HIm, a proton conductivity value of $3.0 \times 10^{-4} \mathrm{~S} \mathrm{~cm}^{-1}$ at $110{ }^{\circ} \mathrm{C}$ is found. Even though the amount of charge carriers in 1-3_HIm is almost equal to the one in 4_HIm, the proton conductivity is at least two orders of magnitude lower $\left(\mathbf{1} \_\right.$HIm $=1.7 \times 10^{-6}, 2$ _HIm $=$ $1.9 \times 10^{-8}$ and 3 _HIm $=1.7 \times 10^{-9} \mathrm{~S} \mathrm{~cm}^{-1}$ ), suggesting that the number of charge carriers is not the most important factor. The activation energy $\left(E_{\text {act }}\right)$ was calculated by fitting the proton conductivity data to the Arrhenius equation. All samples demonstrated Arrhenius behaviour between 80 and $110{ }^{\circ} \mathrm{C}$. The highest value was found for $\mathbf{3} \_\mathbf{H I m}\left(E_{\text {act }}=\right.$ $0.46 \mathrm{eV}$ ), whereas no major distinction was encountered for 2_HIm $\left(E_{\text {act }}=0.41 \mathrm{eV}\right)$ and 1_HIm $\left(E_{\text {act }}=0.42 \mathrm{eV}\right)$. In contrast, the activation energy for $\mathbf{4}$ HIm is by far the lowest $\left(E_{\text {act }}=0.19 \mathrm{eV}\right)$ (Table 3).

\section{Crystal structures}

The crystal structures of Al-MIL-53- $\left(\mathrm{CH}_{3}\right)_{x \_} \operatorname{HIm}(x=0,1,2)$ and CAU-11_HIm were determined from PXRD data by a

Table 2 The amount of imidazole in the compounds 1.1.3HIm (MIL-53_HIm), 2.1.2HIm (MIL-53-CH__HIm), 3.1.1HIm (MIL-53-(CH3) 2 HIm) and 4.1.3 $\mathrm{HIm}$ (CAU-11_HIm), was evaluated by (a) dissolving the compounds in $5 \% \mathrm{NaOD} / \mathrm{D}_{2} \mathrm{O}$ and measuring ${ }^{1} \mathrm{H}-\mathrm{NMR}$ spectra in order to determine the molar ratios of imidazole : linker molecules and (b) comparison of the theoretical (theo. \%) and observed (obs. \%) weight losses as obtained from thermogravimetric analysis (TGA)

\begin{tabular}{|c|c|c|c|c|c|c|c|c|c|c|c|c|}
\hline & \multicolumn{3}{|c|}{ MIL-53_HIm } & \multicolumn{3}{|c|}{ MIL-53-CH $\mathrm{CH}_{3} \mathrm{HIm}$} & \multicolumn{3}{|c|}{ MIL-53- $\left(\mathrm{CH}_{3}\right)_{2} \_\mathrm{HIm}$} & \multicolumn{3}{|c|}{ CAU-11_HIm } \\
\hline & $\begin{array}{l}\text { TGA } \\
\text { theo. } \%\end{array}$ & $\begin{array}{l}\text { Obs. } \\
\%\end{array}$ & $\begin{array}{l}\text { NMR } \\
\text { ratio }\end{array}$ & $\begin{array}{l}\text { TGA } \\
\text { theo. } \%\end{array}$ & $\begin{array}{l}\text { Obs. } \\
\%\end{array}$ & $\begin{array}{l}\text { NMR } \\
\text { ratio }\end{array}$ & $\begin{array}{l}\text { TGA } \\
\text { theo. } \%\end{array}$ & $\begin{array}{l}\text { Obs. } \\
\%\end{array}$ & $\begin{array}{l}\text { NMR } \\
\text { ratio }\end{array}$ & $\begin{array}{l}\text { TGA } \\
\text { theo. } \%\end{array}$ & $\begin{array}{l}\text { Obs. } \\
\%\end{array}$ & $\begin{array}{l}\text { NMR } \\
\text { ratio }\end{array}$ \\
\hline Imidazole & 29.1 & 30.1 & 1.3 & 24.7 & 25.0 & 1.2 & 23.5 & 23.8 & 1.1 & 20.1 & 21.1 & 1.3 \\
\hline Linker & 52.7 & 51.5 & 1.0 & 58.5 & 57.2 & 1.0 & 60.3 & 58.5 & 1.0 & 68.4 & 67.1 & 1.0 \\
\hline $\mathrm{Al}_{2} \mathrm{O}_{3}$ & 16.2 & 16.5 & - & 16.8 & 17.8 & - & 16.0 & 17.7 & - & 11.5 & 11.8 & - \\
\hline
\end{tabular}


Table 3 Overview of the imidazole to $\mu-\mathrm{OH}$ distance within the frameworks, proton conductivity and the resulting activation energy $\left(E_{A}\right)$ from the Arrhenius plot (see Fig. 3)

\begin{tabular}{|c|c|c|c|}
\hline & $\begin{array}{l}\text { Conductivity } \\
{\left[\mathrm{S} \mathrm{cm}^{-1}\right]}\end{array}$ & $\begin{array}{l}\mathrm{O} \cdots \mathrm{N} \text { distance } \\
{[\AA]}\end{array}$ & $\begin{array}{l}E_{\mathrm{A}} \\
{[\mathrm{eV}]}\end{array}$ \\
\hline MIL-53- $\left(\mathrm{CH}_{3}\right)_{2}$ imi & $1.7 \times 10^{-9}$ & 2.71(1) & 0.46 \\
\hline MIL-53-( $\left.\mathrm{CH}_{3}\right) \_i m i$ & $1.9 \times 10^{-8}$ & $3.06(1)$ & 0.41 \\
\hline MIL-53_imi & $1.7 \times 10^{-6}$ & $\geq 3.04(1)$ & 0.42 \\
\hline CAU-11-imi & $3.0 \times 10^{-4}$ & 二- & 0.19 \\
\hline
\end{tabular}

combination of force-field calculations and Rietveld refinement. Details of the experimental procedures and the final Rietveld plots are given in the ESI (Table S1, Fig. S18-S21 †).

The structure of Al-MIL-53 is well known and has been described in great detail elsewhere. ${ }^{21,36,37}$ The frameworks of MIL-53- $\left(\mathrm{CH}_{3}\right)_{x}(x=0,1,2)$ are built up by the same interconnection of infinite chains of trans corner-sharing $\mathrm{AlO}_{4}(\mathrm{OH})_{2}$ polyhedra via the linker molecules. The two carboxylate groups of each BDC- $\mathrm{X}^{2-}$ ion are connected to two adjacent aluminium-oxo-chains each, leading to one-dimensional rhombic channels. Depending on the presence of guest molecules, the diameter of these channels can reversibly change ("breathing"). After activation and impregnation, imidazole molecules could be successfully localized inside the pores of two of the three MIL-53 type compounds, 2_HIm and 3_HIm. The crystal structures of these compounds are shown in Fig. 4 and 5. In the channels of 2_HIm, the guest molecules adsorb in a commensurate fashion and are apparently interacting via hydrogen bonds to the $\mu-\mathrm{OH}$ group ( $\mathrm{N} \cdots \mathrm{O}$ distance of 3.06(1) $\AA$ ). However, the reader should keep in mind that nitrogen and carbon atoms cannot be reliably distinguished and protons cannot be localized from refinements of PXRD data and thus such assignment is based on the observed interatomic distances between the host framework and the guest molecules. The host-guest interactions are also confirmed by IR spectroscopy. Comparison of the IR spectra of 2 and 3 (S15 and

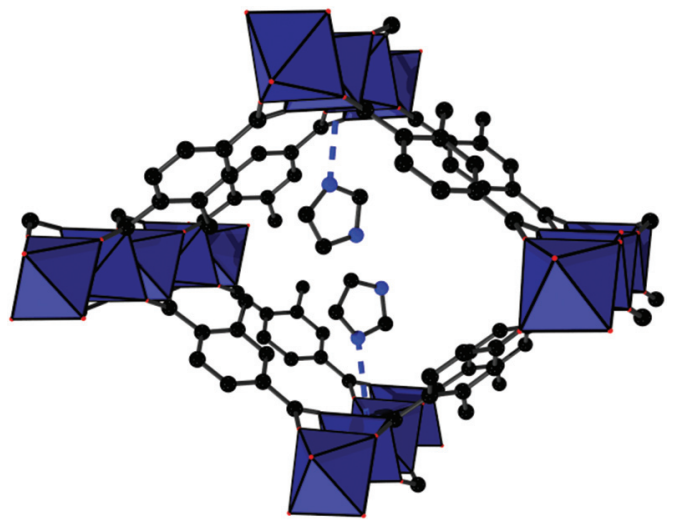

Fig. 4 The crystal structure of Al-MIL-53-CH $\mathrm{CH}_{3} \mathrm{HIm}$. $\mathrm{AlO}_{6}$ polyhedra are shown in dark blue, carbon atoms in black and nitrogen atoms in light blue. The potential hydrogen bonds between the $\mu-\mathrm{OH}$ groups and the guest molecules are shown as dashed blue lines.

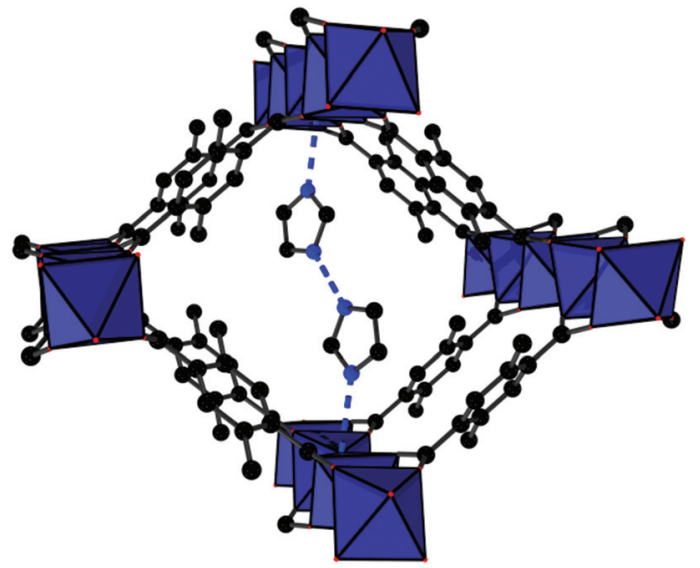

Fig. 5 The crystal structure of Al-MIL-53- $\left(\mathrm{CH}_{3}\right)_{2}-\mathrm{HIm}$. AlO 6 polyhedra are shown in dark blue, carbon atoms in black and nitrogen atoms in light blue. The potential hydrogen bonds are shown as dashed blue lines.

S16 $\dagger$ ), before and after impregnation, show a decreasing signal intensity in the range $3600-3700 \mathrm{~cm}^{-1}$ upon impregnation. Bearing in mind that this signal can be attributed to the stretching vibration of the $\mu$-OH group of the framework, ${ }^{28}$ it hints to hydrogen bonding interactions with HIm molecules. Furthermore, only a weak signal at $2850 \mathrm{~cm}^{-1}$ is visible, indicating weakly self-associated imidazole molecules within the pores. ${ }^{38}$ In the structure of 3_HIm, the guest molecules adsorb in a similar fashion but with shorter and therefore also stronger hydrogen bonds to the host framework ( $\mathrm{N} \cdots \mathrm{O}$-distance of 2.71(1) A). In addition, weaker hydrogen bonds between adjacent guest molecules in the pores are found. The strong binding in 3_HIm is in good agreement with the lowest conductivity observed among all four samples.

The weaker binding in 2_HIm also correlates with the increase in proton conductivity by one order of magnitude.

For 1_HIm, a sample loaded with approximately 1.3 imidazole molecules per formula unit was analysed by Rietveld refinement. The guest molecules assemble in two different positions, one of them shown in Fig. 6, which agrees well with the two weight loss steps observed in the TG-experiment between $120-270{ }^{\circ} \mathrm{C}$.

However, the crystallographically independent molecules are disordered in a manner which is not chemically reasonable since this would lead to a strong overlap between the molecules. We interpret this as non-ordered adsorption of the guest molecules without full ordering of the imidazole molecules inside the channels. Nevertheless, a short distance between the host and the guest molecules with lower occupancy (accounting for $\approx 42 \%$ of the guest molecules) could indicate weak interactions via hydrogen bonding (N...O-distance of 3.04(1) $\AA$, Fig. 6). The majority of guest molecules $(\approx 58 \%)$ assemble in a distance from the framework that indicates no relevant interactions (host-guest distance $>3.4 \AA$ A). Nevertheless, IR spectroscopy for 1_HIm (Fig. S14 $\dagger$ ) does show a sharp stretching vibration of the $\mu-\mathrm{OH}$ group after 


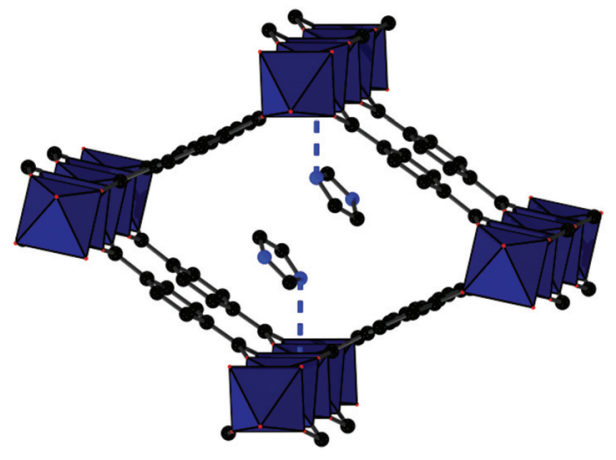

Fig. 6 Crystal structure of Al-MIL-53_HIm with some of the imidazole molecules binding to the host framework (view along the channels). $\mathrm{AlO}_{6}$ polyhedra are shown in dark blue, carbon atoms in black and nitrogen atoms in light blue. The potential hydrogen bonds between the $\mu$ $\mathrm{OH}$ groups and the guest molecules in Al-MIL-53_HIm are shown as dashed blue lines. Please note that most guest molecules adsorbed in Al-MIL-53 (not shown here) assemble in a "random" fashion which we interpret as non-ordered adsorption.

impregnation with imidazole, indicating fewer interactions between the guest molecules and the framework itself. While this interpretation is not unambiguous, it is in very good agreement with the increase in proton conductivity of $\mathbf{1}$ _HIm by two orders of magnitude compared to 2_HIm and three orders of magnitude compared to $\mathbf{3}$ _HIm. Based on these results, we chose CAU-11 as a suitable host to further increase the conductivity. In the structure of CAU-11, the same inorganic building unit as in Al-MIL-53 is observed (Fig. 7). The chains are interconnected along the $a$-axis via the carboxylate groups of the linker molecules, resulting in layers with lozenge-shaped pores. Due to the interaction of sulfone groups with the inorganic building unit, a layered structure (ABAB-type stacking) is formed, creating a hydrophobic inner-pore surface. Thus the $\mu-\mathrm{OH}$ groups are already interacting with the sulfone groups and should therefore not affect the conductivity of an imidazole loaded MOF.

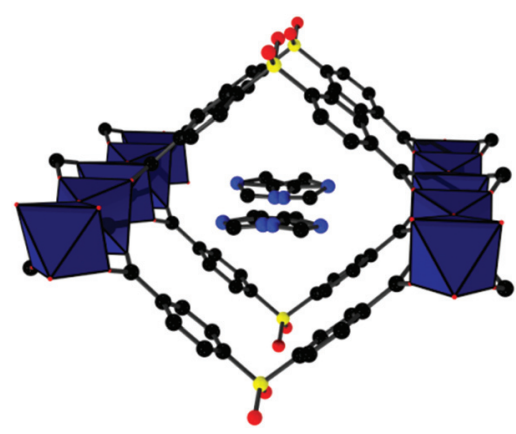

Fig. 7 Crystal structure of CAU-11_HIm with some of the imidazole molecules (view along the channels). $\mathrm{AlO}_{6}$ polyhedra are shown in dark blue, carbon atoms in black and nitrogen atoms in light blue. Please note that all guest molecules adsorbed in CAU-11 assemble in a "random" fashion which we interpret as non-ordered adsorption.
A closer look at the IR-spectra of 4 before and after impregnation with imidazole shows a distinct signal at $\sim 3580 \mathrm{~cm}^{-1}$, indicating no interaction between the imidazole and the $\mu-\mathrm{OH}$ group of the framework. Indeed, the imidazole molecules in 4_HIm assemble in the centre of the channels (host-guest distance $>3.4 \AA$ A Fig. 7). As observed for 1_HIm, the molecules overlap in a manner which is not chemically reasonable and thus we interpret this as non-ordered adsorption. Furthermore, the IR spectra for 1_HIm and 4_HIm show distinct signals at $2850 \mathrm{~cm}^{-1}$, which can be explained by the selfassociation of imidazole molecules to oligomers, ${ }^{38}$ suggesting hydrogen-bonding interactions between the imidazole molecules within the pores. This is substantiated by another increase in proton conductivity by two orders of magnitude, compared to 1_HIm.

In summary, we incorporated imidazole into the pores of the MOFs Al-MIL-53-( $\left.\mathrm{CH}_{3}\right)_{x}(x=0,1,2)$ and CAU-11. Imidazole molecules could be successfully localized inside the pores of Al-MIL-53-( $\left.\mathrm{CH}_{3}\right)_{x \_}$HIm (1_HIm, 2_HIm, 3_HIm) using PXRD data by a combination of force-field calculations and Rietveld refinement. Hydrogen bonds of varying strength were found for 1-3_HIm between the $\mu-\mathrm{OH}$ groups of the framework and the nitrogen atom of the imidazole molecules. The different values of conductivity of 1-3_HIm are consistent with the distance between the $\mu-\mathrm{OH}$ group and the imidazole molecule (Table 3). In addition, we used CAU-11 as a host to further increase the conductivity, as the structure of CAU-11 exhibits a hydrophobic inner-pore surface (4_HIm). This results in a proton conductivity two orders of magnitude higher than the best Al-MIL-53- $\left(\mathrm{CH}_{3}\right)_{x_{-}} \mathrm{HIm}$ compound $\left(3.0 \times 10^{-4} \mathrm{~S} \mathrm{~cm}^{-1}\right)$, and is also reflected in the activation energy which is significantly lower for 4_HIm $(0.19 \mathrm{eV})$ compared to 1-3_HIm.

\section{Conclusions}

The observed ordering effect on the imidazole molecules through interactions with hydrophilic $\mu-\mathrm{OH}$ groups within the framework leads to a direct influence on the conductivity of the host-guest compounds. Within this context, it was found that the most hydrophobic framework yields the most conductive host-guest materials. We propose that the introduction of hydrophilic groups leads to the break-down of hydrogen-bonded chains of imidazole molecules (oligomers) within the host framework. In consequence, the hydrophilic groups of the framework might slow down the rearrangement of the HIm molecules, which is causing a drop in proton conductivity. Further NMR-spectroscopic studies on the compounds are currently carried out. In addition, it would be compelling to investigate other hydrophobic frameworks towards their beneficial properties regarding the proton conductivity. Furthermore, it is necessary to address if similar effects can be found for other guest molecules possessing, for example, more acidic properties. 


\section{Acknowledgements}

This project was supported by the German Science Foundation (STO 643/10-1 and WA 1116/17-2). Thomas Homburg thanks the Deutsche-Bundesstiftung-Umwelt (DBU) and the Deutscher Akademischer Austauschdienst (DAAD) for financial support.

\section{Notes and references}

1 A. Iulianelli, P. Ribeirinha, A. Mendes and A. Basile, Renewable Sustainable Energy Rev., 2014, 29, 355-368.

2 S. Holdcroft, Chem. Mater., 2014, 26, 381-393.

3 S. Subianto, M. Pica, M. Casciola, P. Cojocaru, L. Merlo, G. Hards and D. J. Jones, J. Power Sources, 2013, 233, 216-230.

4 A. Chandan, M. Hattenberger, A. El-kharouf, S. Du, A. Dhir, V. Self, B. G. Pollet, A. Ingram and W. Bujalski, J. Power Sources, 2013, 231, 264-278.

5 Y. Ye, X. Wu, Z. Yao, L. Wu, Z. Cai, L. Wang, X. Ma, Q.-H. Chen, Z. Zhang and S. Xiang, J. Mater. Chem., 2016, 4, 4062-4070.

6 Y. Ye, L. Zhang, Q. Peng, G.-E. Wang, Y. Shen, Z. Li, L. Wang, X. Ma, Q.-H. Chen, Z. Zhang and S. Xiang, J. Am. Chem. Soc., 2015, 137, 913-918.

7 S. Liu, Z. Yue and Y. Liu, Dalton Trans., 2015, 44, 1297612980.

8 D. Umeyama, S. Horike, M. Inukai, T. Itakura and S. Kitagawa, J. Am. Chem. Soc., 2012, 134, 12780-12785.

9 S. Horike, W. Chen, T. Itakura, M. Inukai, D. Umeyama, H. Asakura and S. Kitagawa, Chem. Commun., 2014, 50, 10241-10243.

10 M. Inukai, S. Horike, D. Umeyama, Y. Hijikata and S. Kitagawa, Dalton Trans., 2012, 41, 13261-13263.

11 J. A. Hurd, R. Vaidhyanathan, V. Thangadurai, C. I. Ratcliffe, I. L. Moudrakovski and G. K. H. Shimizu, Nat. Chem., 2009, 1, 705-710.

12 D. Umeyama, S. Horike, M. Inukai, Y. Hijikata and S. Kitagawa, Angew. Chem., Int. Ed., 2011, 50, 11706-11709.

13 P. Ramaswamy, N. E. Wong and G. K. H. Shimizu, Chem. Soc. Rev., 2014, 43, 5913-5932.

14 D. Ye, Z. Tu, Y. Yu, Y. Cai, H. Zhang, Z. Zhan and M. Pan, Int. J. Energy Res., 2014, 38, 1181-1191.

15 P. Choi, N. H. Jalani, T. M. Thampan and R. Datta, J. Polym. Sci., Part B: Pol. Phys., 2006, 44, 2183-2200.

16 D. K. Paul, A. Fraser and K. Karan, Electrochem. Commun., 2011, 13, 774-777.

17 K.-D. Kreuer, Chem. Mater., 1996, 8, 610-641.

18 S. J. Hamrock and M. A. Yandrasits, Polym. Rev., 2006, 46, 219-244.
19 W. Chen, S. Horike, D. Umeyama, N. Ogiwara, T. Itakura, C. Tassel, Y. Goto, H. Kageyama and S. Kitagawa, Angew. Chem., Int. Ed., 2016, 55, 5195-5200.

20 B.-L. Liu, H.-Y. Zang, H.-Q. Tan, Y.-H. Wang and Y.-G. Li, CrystEngComm, 2016, 18, 3300-3305.

21 A. S. Munn, R. S. Pillai, S. Biswas, N. Stock, G. Maurin and R. I. Walton, Dalton Trans., 2016, 45, 4162-4168.

22 N. Reimer, B. Bueken, S. Leubner, C. Seidler, M. Wark, D. De Vos and N. Stock, Chem. - Eur. J., 2015, 21, 1251712524.

23 T. N. Tu, N. Q. Phan, T. T. Vu, H. L. Nguyen, K. E. Cordova and H. Furukawa, J. Mater. Chem. A, 2016, 4, 36383641.

24 T. Yamada, K. Otsubo, R. Makiura and H. Kitagawa, Chem. Soc. Rev., 2013, 42, 6655-6669.

25 M. Yoon, K. Suh, S. Natarajan and K. Kim, Angew. Chem., Int. Ed., 2013, 52, 2688-2700.

26 S. Bureekaew, S. Horike, M. Higuchi, M. Mizuno, T. Kawamura, D. Tanaka, N. Yanai and S. Kitagawa, Nat. Mater., 2009, 8, 831-836.

27 T. Loiseau, C. Serre, C. Huguenard, G. Fink, F. Taulelle, M. Henry, T. Bataille and G. Férey, Chem. - Eur. J., 2004, 10, 1373-1382.

28 S. Biswas, T. Ahnfeldt and N. Stock, Inorg. Chem., 2011, 50, 9518-9526.

29 E. Eisbein, J.-O. Joswig and G. Seifert, Microporous Mesoporous Mater., 2015, 216, 36-41.

30 N. Reimer, H. Reinsch, A. K. Inge and N. Stock, Inorg. Chem., 2015, 54, 492-501.

31 A. I. Materials, Studio Version 5.0, San Diego, CA, 2009.

32 C. S. Topas, Academics 4.2, 2007.

$33 \mathrm{~J}$. R. Macdonald and W. B. Johnson, in Impedance Spectroscopy, John Wiley \& Sons, Inc., 2nd Edition edn, 2005, DOI: 10.1002/0471716243.ch1.

34 G. Alberti, M. Casciola, L. Massinelli and B. Bauer, J. Membr. Sci., 2001, 185, 73-81.

35 T. Devic, P. Horcajada, C. Serre, F. Salles, G. Maurin, B. Moulin, D. Heurtaux, G. Clet, A. Vimont, J.-M. Grenèche, B. L. Ouay, F. Moreau, E. Magnier, Y. Filinchuk, J. Marrot, J.-C. Lavalley, M. Daturi and G. Férey, J. Am. Chem. Soc., 2010, 132, 1127-1136.

36 H. Reinsch, R. S. Pillai, R. Siegel, J. Senker, A. Lieb, G. Maurin and N. Stock, Dalton Trans., 2016, 45, 41794186.

37 P. G. Yot, Z. Boudene, J. Macia, D. Granier, L. Vanduyfhuys, T. Verstraelen, V. Van Speybroeck, T. Devic, C. Serre, G. Ferey, N. Stock and G. Maurin, Chem. Commun., 2014, 50, 9462-9464.

38 H. Wolff, H. Müller and H. Müller, Ber. Bunsenges. Phys. Chem., 1974, 78, 1241-1244. 